\title{
Medicanes in an ocean-atmosphere coupled regional climate model
}

\author{
N. Akhtar ${ }^{1,2}$, J. Brauch ${ }^{2,3}$, A. Dobler ${ }^{4}$, K. Béranger ${ }^{5}$, and B. Ahrens ${ }^{1,2}$ \\ ${ }^{1}$ Institute for Atmospheric and Environmental Sciences, Goethe University, Frankfurt am Main, Germany \\ ${ }^{2}$ Biodiversity and Climate Research Center, Frankfurt am Main, Germany \\ ${ }^{3}$ German Weather Service, Offenbach am Main, Germany \\ ${ }^{4}$ Institute of Meteorology, Free University of Berlin, Berlin, Germany \\ ${ }^{5}$ Unité de Mécanique, ENSTA-ParisTech, Palaiseau, France \\ Correspondence to: N. Akhtar (naveed.akhtar@iau.uni-frankfurt.de)
}

Received: 12 February 2014 - Published in Nat. Hazards Earth Syst. Sci. Discuss.: 19 March 2014

Revised: 13 June 2014 - Accepted: 6 July 2014 - Published: 26 August 2014

\begin{abstract}
So-called medicanes (Mediterranean hurricanes) are meso-scale, marine, and warm-core Mediterranean cyclones that exhibit some similarities to tropical cyclones. The strong cyclonic winds associated with medicanes threaten the highly populated coastal areas around the Mediterranean basin. To reduce the risk of casualties and overall negative impacts, it is important to improve the understanding of medicanes with the use of numerical models. In this study, we employ an atmospheric limited-area model (COSMOCLM) coupled with a one-dimensional ocean model (1-D NEMO-MED12) to simulate medicanes. The aim of this study is to assess the robustness of the coupled model in simulating these extreme events. For this purpose, 11 historical medicane events are simulated using the atmosphereonly model, COSMO-CLM, and coupled model, with different setups (horizontal atmospheric grid spacings of 0.44 , 0.22 , and $0.08^{\circ}$; with/without spectral nudging, and an ocean grid spacing of $1 / 12^{\circ}$ ). The results show that at high resolution, the coupled model is able to not only simulate most of medicane events but also improve the track length, core temperature, and wind speed of simulated medicanes compared to the atmosphere-only simulations. The results suggest that the coupled model is more proficient for systemic and detailed studies of historical medicane events, and that this model can be an effective tool for future projections.
\end{abstract}

\section{Introduction}

The Mediterranean Sea is known to be one of the main cyclogenetic regions in the world (Pettersen, 1956; Hoskins and Hodges, 2002; Wernli and Schwierz, 2006). A certain type of cyclone in the Mediterranean Sea with physical and structural similarities to tropical cyclones is known as a medicane (Mediterranean hurricane). Medicanes are meso-scale cyclones (the diameter is usually less than $300 \mathrm{~km}$ ), with a rounded structure and a cloudless area at the center. Other features include a warm core and intense low sea level pressure, combined with strong cyclonic winds and heavy rainfall (Businger and Reed, 1989). In general, the intensity of medicanes is much weaker than tropical hurricanes (Moscatello et al., 2008); however, a few medicanes have reached tropical hurricane strengths $\left(33 \mathrm{~m} \mathrm{~s}^{-1}\right)$. Strong surface heat fluxes and deep convection are important initial conditions in the formation of medicanes. The triggering mechanisms involved in this development are the presence of cold anomalies in the high troposphere, surface heat fluxes (latent and sensible), low wind shear, and high low-level vorticity (Cavicchia et al., 2013). According to Trenberth (2005), the minimum value of sea surface temperature (SST) to develop a tropical hurricane is $26^{\circ} \mathrm{C}$. However, in 2005 hurricane Vince developed on $24^{\circ} \mathrm{C} \mathrm{SST} \mathrm{(http://www.nhc.noaa.gov/archive/}$ 2005/dis/al232005.discus.001.shtml). Studies show that the SST has to be higher than $15^{\circ} \mathrm{C}$ for medicanes (Tous and Romero, 2013). As with tropical hurricanes, the air-sea temperature difference plays an important role in the development of medicanes (Palmen, 1948; Miglietta et al., 2011). In 
the case of tropical hurricanes, SST creates the conditions of thermodynamical disequilibrium that trigger the development of a vortex, whereas in the case of medicanes, the interplay between the temperature at the surface and upper atmospheric layer plays a key role in their development (Cavicchia et al., 2013). The ocean also plays an important role in the intensity of tropical cyclones (Emanuel, 1986; Emanuel and Rotunno, 1987); similarly, the ocean feedback is also crucial in the development of medicanes. Table 1 shows a list of medicane events from 1983 to 2003, their approximate times of mature phase, sizes and geographical positions (Tous and Romero, 2013). Spatially, the central and western parts of the Mediterranean Sea are the main genesis regions of medicanes. Most of the events occurred during autumn and winter, but some were observed during the spring season.

Medicanes have a high potential for destruction in the densely populated coastal areas around the Mediterranean Sea. To reduce the risk of casualties and overall negative impacts, better knowledge of medicanes is essential for potential prediction. Due to their meso-scale and marine characteristics, medicanes are not well represented in automatic detection methods. The lack of dense observations over sea, and the occasional occurrence of medicanes make it more difficult to recognize meteorological features associated with them (Tous and Romero, 2013). Surface observations of such storms are limited to ships crossing nearby; in situ weather reports are generally poor. One of the main sources of observations of medicanes with full coverage are satellite images available since 1980. Several studies have been carried out based on the observational evidence (e.g., Ernst and Matson, 1983; Rasmussen and Zick, 1987; Luque et al., 2007; Moscatello et al., 2008) and combined, model and observations (e.g., Miglietta et al., 2013; Conte et al., 2011). Most of the contemporary modeling studies on medicanes are done by dynamical downscaling using regional atmosphere-only models (e.g., Homar et al., 2003; Fita et al., 2007; Miglietta et al., 2011; Cavicchia et al., 2013).

Coarse global climate models cannot fully resolve the complex orography and other important local processes such as the bora, mistral, and etesian winds, and the deepwater formations that characterize the Mediterranean region. Therefore, the air-sea fluxes over this region are not correctly represented in a coarse global climate model (Elguindi et al., 2009). Recent studies show that high-resolution coupled models over the Euro-Mediterranean region significantly improve the representation of air-sea fluxes (Gualdi et al., 2012; Dubois et al., 2012; Artale et al., 2010; Somot et al., 2008). In another study, Sanna et al. (2013) have shown that SSTs simulated through a high-resolution eddypermitting ocean model have strong and beneficial effects on precipitation and cyclogenesis simulation.

The SSTs in regional atmosphere-only runs are prescribed and derived from reanalysis data such as the European Center for Medium-Range Weather Forecasts (ECMWF) Reanalysis Interim (ERA-Interim), which also include satellite observa-
Table 1. Code, date, approximate time of mature phase and geographical coordinates of medicane centers from 1983 to 2003 (Tous and Romero, 2013).

\begin{tabular}{lrccccc}
\hline Code & Date & $\begin{array}{c}\text { Time } \\
(\mathrm{UTC})\end{array}$ & $\begin{array}{c}\text { Lat } \\
\left({ }^{\circ} \mathrm{N}\right)\end{array}$ & $\begin{array}{c}\text { Long } \\
\left({ }^{\circ} \mathrm{E}\right)\end{array}$ & $\begin{array}{c}\text { Maximum } \\
\text { diameter } \\
(\mathrm{km})\end{array}$ & $\begin{array}{c}\text { Lifetime } \\
(\mathrm{h})\end{array}$ \\
\hline ME01 & 29 Sep 1983 & $12: 00$ & 41.1 & 6.8 & 220 & 90 \\
ME02 & 7 Apr 1984 & $06: 00$ & 36.4 & 19.2 & 230 & 36 \\
ME03 & 29 Dec 1984 & $06: 00$ & 35.4 & 11.6 & 220 & 60 \\
ME04 & 14 Dec 1985 & $12: 00$ & 35.5 & 17.6 & 290 & 54 \\
ME05 & 5 Dec 1991 & $12: 00$ & 36.2 & 16.7 & 320 & 30 \\
ME06 & 15 Jan 1995 & $18: 00$ & 36.4 & 19.1 & 300 & 78 \\
ME07 & 12 Sep 1996 & $12: 00$ & 39.4 & 2.8 & 170 & 12 \\
ME08 & 6 Oct 1996 & $18: 00$ & 37.2 & 3.9 & 240 & 90 \\
ME09 & 10 Dec 1996 & $00: 00$ & 40.3 & 3.7 & 230 & 48 \\
ME10 & 26 Jan 1998 & $12: 00$ & 36.7 & 17.9 & 250 & 30 \\
ME11 & 19 Mar 1999 & $06: 00$ & 38.5 & 19.6 & 250 & 30 \\
ME12 & 27 May 2003 & $00: 00$ & 40.1 & 2.8 & 280 & 42 \\
\hline
\end{tabular}

tions. The quality of SSTs in this reanalysis is in good agreement with the observations (Simmons et al., 2006). However, due to the small size and short lifetimes of medicanes, the quality of the reanalysis data is compromised by the coarse time and space resolution. Most reanalysis data sets are available in $6 \mathrm{~h}$ intervals, whereas medicanes occur on short timescales (ranging from 12 to $90 \mathrm{~h}$ ). Fine-scale feedback associated with air-sea interactions can influence the temporal and spatial structure of medicanes. A fully coupled regional model with adequate resolution could be useful for future projections and historical evaluation of these extreme events.

In the present study, a regional atmosphere-only and coupled model are examined for their robustness and stability in simulating the formation and life cycle of medicanes using different setups (horizontal grid spacings of $0.44,0.22$, and $0.08^{\circ}$ and an ocean grid spacing of $1 / 12^{\circ}$ ). By applying spectral nudging to the atmospheric model, the same medicane events are also simulated in both coupled and atmosphere-only setups. The primary goal of this study is to investigate the impact of the air-sea interactions in the coupled model on the intensity of medicanes, as compared to the atmosphere-only model and adequate atmospheric grid resolution essential to resolve medicane features.

\section{Experimental setup}

In this study, the regional climate model COSMO-CLM v4.8 (CCLM), based on non-hydrostatic equations (Rockel et al., 2008), is used for the atmosphere-only simulations, and a recently developed regional ocean-atmosphere coupled model - consisting of an atmosphere component, CCLM, and an ocean component, NEMO-MED12 v3.2 - is used for the coupled simulations. The NEMO-MED12 is the regional part of the global ocean model NEMO v3.2 (Madec, 2008), specially tuned for the Mediterranean Sea (for more details 
see, e.g., Lebeaupin et al., 2011). Along with a full threedimensional (3-D) configuration, the NEMO system also includes a one-dimensional (1-D) configuration that simulates a stand-alone water column. The 1-D NEMO can be applied to the ocean alone or to the ocean-ice system (Akhtar, 2013). Vertical exchange processes across the air-sea boundary and vertical mixing throughout the water column affect the local conditions more rapidly and effectively than horizontal advection and mixing processes on short timescales (up to 1 year) (Niiler and Kraus, 1977). Therefore, the horizontal gradients are assumed to be zero between water columns in 1-D models. The 1-D models can perform multiple model simulations in a relatively short time with simplified dynamics. In contrast, 3-D ocean models are computationally expensive and time-consuming, but include full 3-D dynamics. The 1-D models are very useful for short time simulations, especially in coupled ocean-atmosphere modeling, to investigate extreme events. The validation of a 1-D compared to a fully 3-D configuration has been conducted in a previous study (Akhtar, 2013). The 1-D NEMO-MED12 is now coupled via the OASIS3 coupler (Valcke, 2013) to CCLM. The 1-D NEMO-MED12 is employed with a basin-wide (covering the whole Mediterranean Sea and part of the Atlantic Ocean), single-column approach where each water column is isolated from the others. Each grid point in the 1-D NEMOMED12 is treated as a single water column. The coupling process is executed every hour, where 1-D NEMO-MED12 passes SST to CCLM and, in exchange heat, momentum, and freshwater fluxes are obtained. A similar setup has been used by Van Pham et al., (2014) for the North and Baltic seas.

Different resolutions of CCLM $-0.44^{\circ}(\sim 50 \mathrm{~km}, 118 \times 83$ grid points, and $32 \sigma$ levels $), 0.22^{\circ}(\sim 25 \mathrm{~km}, 206 \times 120$ grid points, and $32 \sigma$ levels $)$, and $0.08^{\circ}(\sim 9 \mathrm{~km}, 536 \times 295$ grid points, and $40 \sigma$ levels) that cover the Med-CORDEX domain (http://www.medcordex.eu) - are employed. For both the coupled and atmosphere-only simulations, the horizontal diffusion parameters in CCLM are tuned for better realization of medicanes. The factors to reduce the standard coefficient for numerical diffusion in case of humidity, cloud water, temperature and pressure smoothing are set to zero. The Runge-Kutta numerical scheme in CCLM is used for both the coupled and atmosphere-only simulations. The 1D NEMO-MED12 has a resolution of $1 / 12^{\circ}(\sim 6$ to $8 \mathrm{~km}$ in latitude and $\sim 8.5 \mathrm{~km}$ in longitude, $567 \times 264$ grid points, and 50 vertical levels), which remains the same for all the coupled runs. The atmospheric model uses ERA-Interim reanalysis data from the ECMWF for both the coupled and atmosphere-only runs. However, in the coupled runs, SST over the Mediterranean Sea is calculated by 1-D NEMOMED12 and elsewhere prescribed and derived from the reanalysis data. The monthly mean seasonal climatology from MEDATLAS-II (Rixen, 2012) is used to initialize 1-D NEMO-MED12.

The coupled and atmosphere-only models are used to simulate the historically listed medicane events from 1983 to
1999 (Table 1), at three different resolutions $(0.44,0.22$, and $\left.0.08^{\circ}\right)$. The same set of simulations are also perfumed with the spectral nudging technique (von Storch et al., 2000). In a study, Cavicchia and von Storch (2012) showed that the performance of CCLM to simulate the medicanes could be improved by applying the spectral nudging technique, particularly the spatial and temporal locations of the simulated medicanes. The spectral nudging was applied on the wind field components above $850 \mathrm{hPa}$ in the interior domain with the aim to keep the large-scale circulation close to the reanalysis data (Cavicchia and von Storch, 2012). The spectral nudging was applied at scales coarser than four ERA-Interim grid lengths. The wind field components at the lower levels are free to interact with local orography and other surface roughness features. The purpose of employing spectral nudging is to analyze its impact on the coupled simulations, as compared to the atmosphere-only simulations, and not to address the time and location of simulated medicanes. The main aim of this study is to examine the ability of the coupled model to simulate the medicanes compared to the atmosphere-only simulations with and without spectral nudging, and to validate it with observations.

Except the differences in atmospheric grid resolutions $\left(0.44,0.22\right.$, and $\left.0.08^{\circ}\right)$, all other configurations of CCLM remain the same in all the atmosphere-only and coupled without spectral nudging simulations. The same holds for spectral nudging simulations. For the remainder of this discussion, we used the abbreviations "CPLXXYY" for the coupled, and "CCLMXXYY" for the atmosphere-only simulations, where "XX" refers to the resolution (" 44 " for $0.44^{\circ}$, " 22 " for $0.22^{\circ}$, and " $08^{\prime}$ " for $0.08^{\circ}$ ), and "YY" refers to spectral nudging ("sn").

Based on the satellite (infrared Meteosat) imagery analysis, 12 cases are documented from 1983 to 2003 (Table 1). The selection criteria of these events were based on cloud structure, size, and lifetime of the cyclones (Tous and Romero, 2013). Because of the limited availability of the MEDATLAS-II climatology (1945-2002), only the first 11 medicane events from 1980 to 1999 are included in this study. Since the last event occurred in 2003 (Table 1), MEDATLAS-II climatology is not available to initialize the ocean model. For each medicane event, both the coupled and atmosphere-only simulations with and without spectral nudging are conducted over a period of 1 month, starting approximately 3 weeks prior to formation of the medicane. The reason of starting simulations 3 weeks before the medicane formation is to have a couple of weeks ocean spin-up in the coupled simulations. To be consistent with the coupled simulations, we used the same period in the atmosphere-only simulations (with ERA-Interim SST forcing).

The following data sets are used for validation:

- For wind speed, the NOAA "SeaWinds" data set, available from 9 July 1987 to the present, is used. The product contains global high-resolution ocean winds and 
wind stresses at $6 \mathrm{~h}$ intervals on a $0.25^{\circ}$ grid (Zhang et al., 2006). SeaWinds are generated by blending observations from multiple satellites.

- For sea level pressure and temperature, NASA's MERRA reanalysis (Rienecker et al., 2011), presently available from 1 January 1979 to 30 September 2013, is used. The state-of-the-art MERRA reanalysis products are available globally for $6 \mathrm{~h}$ intervals at $0.5^{\circ}$ resolution, and 42 vertical levels.

\section{Results and discussion}

In this section, we discuss the ability of the coupled and atmosphere-only model to simulate the medicanes at different resolutions with and without applying the spectral nudging technique. The meteorological variables, sea level pressure, temperature at mid-troposphere (in our case, $700 \mathrm{hPa}$ level), and $10 \mathrm{~m}$ wind speeds, are analyzed. To simulate a medicane, one needs to find intense sea level pressure minima, a warm core at mid-troposphere, and strong cyclonic winds (Tous et al., 2013). The medicane tracks are constructed by following the sea level pressure minima in hourly model outputs in a grid box with less than $40 \%$ of land fraction. The same method is used to construct the medicanes track in the MERRA reanalysis data. Due to the coarse temporal resolution of the MERRA reanalysis data $(6 \mathrm{~h})$, it is not possible to track the full trajectories of medicanes. Therefore, only approximated tracks are shown here for MERRA reanalysis. Although the spatial resolution of the MERRA reanalysis data is coarse $\left(0.5^{\circ}\right)$, medicane features such as mean sea level pressure and warm-core structure are reasonably well represented due to the assimilation of observations such as satellite data. For the medicane's starting and ending times, we took the information available from satellite images on the website http://www.uib.es/depart/dfs/ meteorologia/METEOROLOGIA/MEDICANES.

We selected 4 different cases from 11 simulated medicane events for detailed validation and discussion. Our choices are motivated by the locations and sizes of these particular medicane events. We chose two cases (ME08 and ME09) from the western region of the Mediterranean Sea, and two (ME06 and ME10) from the central region. Two cases, ME06 from the central region and ME08 from the west, had maximum lifetimes, and two cases, ME10 from the central region and ME09 from the west, had intermediate lifetimes (Table 1). Due to unavailability of the NOAA data set before 9 July 1987, only cases that occurred after 1988 were selected.

\subsection{Case ME08}

The ME08 case was recorded to have a lifetime of $90 \mathrm{~h}$, making it one of the longest listed medicane events (Table 1). The medicane started to develop north of Algeria and reached maximum strength while it was moving between the Balearic Islands and Sardinia. Strong winds and severe damage were reported in the Aeolian Islands (north of Sicily). The medicane crossed Calabria and dissipated after making landfall in the coastal regions of Greece. The snapshots of coupled simulations at the three resolutions mentioned above, on 6 October at 03:00 UTC (30 min before the development of ME08), show a large-scale baroclinic disturbance that evolved over the western part of the Mediterranean Sea (Fig. 1). This intrusion of cold air into the upper and mid-troposphere can favor the development of medicanes. The synoptic-scale analysis shows that medicanes are not fully isolated structures of atmospheric circulation (Emanuel, 2005; Homar et al., 2003; Pytharoulis et al., 2000). Two dynamical processes are involved in the development of medicanes: the first phase is dominated by the baroclinic development, and the second is driven by convective tropical-like activity and air-sea interactions. The large-scale disturbance is well represented in CPL44, CPL22, and CLP08 simulations, and similar results are also observed in CCLM44, CCLM22, and CCLM08 (not shown here). According to the satellite observations, on 6 October at 03:30 UTC, the disturbance turned into a medicane that reached its mature phase at 18:00 UTC (Table 1). Figure 2 shows the mean sea level pressure and temperature in the mid-troposphere ( $700 \mathrm{hPa}$ pressure level) on 7 October, at 18:00 UTC, along with the medicane track (black dots). In this case the medicane eye developed twice (7 October at 06:30 UTC and 8 October at 12:00 UTC). In CPL44 and CCLM44 simulations, the typical medicane signals (such as intense mean sea level pressure, warm core and cyclonic winds) are not found. However, the medicane track is reasonably well represented in CCLM22 and CPL22, and even finer and more intense in CPL08 and CCLM08 (Fig. 2). The length of the simulated medicane track in CPL22 is shorter (74 h) compared to CCLM22 (90 h). The lowest minimum sea level pressure values, lifetimes, and start and end dates of all the simulated medicanes are shown in Table 2.

The track and warm-core structure of the medicane are better resolved and represented in $0.08^{\circ}$ simulations, and are in good agreement with the MERRA reanalysis data (Fig. 2). This is due to the meso-scale characteristic of medicanes, which are not fully resolved at low resolutions $(0.44$ and $\left.0.22^{\circ}\right)$. The sea level pressure minimum appeared $1 \mathrm{~h}$ earlier in CPL08 compared to the CCLM08 simulations, and the warm core is more prominent in the CPL08 simulations. The medicane track length in CPL08 is $94 \mathrm{~h}, 92 \mathrm{~h}$ in CCLM08 and $72 \mathrm{~h}$ in MERRA reanalysis (Table 2). The medicane track in CPL08 is improved compared to CCLM08, and according to the MERRA reanalysis, with a more accurate position near the Sicily channel.

Figure 3 shows the wind speed patterns in all the simulations $\left(0.44,0.22\right.$, and $\left.0.08^{\circ}\right)$ of the ME08 event and the NOAA data set on 7 October at 18:00 UTC. The high wind speeds associated with the medicane are not observed in the CPL44 and CCLM44 simulations. Compared to this, 


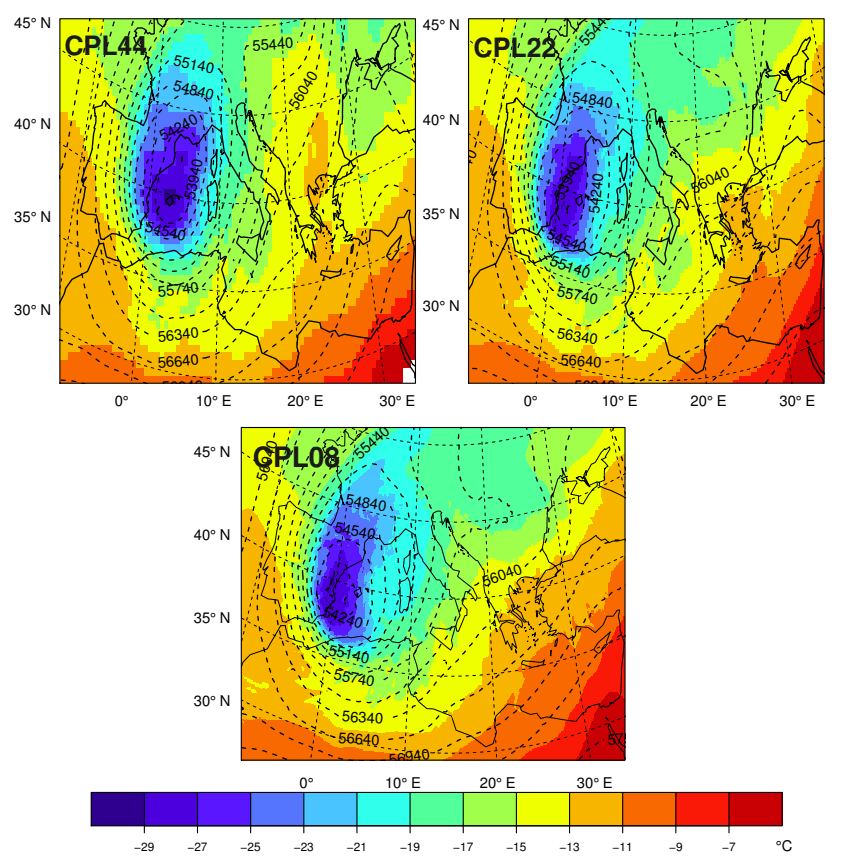

Figure 1. ME08; geopotential height $\left(\mathrm{m}^{2} \mathrm{~s}^{-2}\right.$; dotted contours lines at $300 \mathrm{~m}^{2} \mathrm{~s}^{-2}$ intervals) and temperature $\left({ }^{\circ} \mathrm{C}\right.$; colored contours at $2{ }^{\circ} \mathrm{C}$ intervals) at $500 \mathrm{hPa}$ in the coupled $\left(0.44,0.22\right.$, and $\left.0.08^{\circ}\right)$ simulations on 6 October 1996 at 03:00 UTC.

the wind speeds in the CPL22 and CCLM22 simulations are slightly improved, but still do not match the high values of the NOAA data set. There is further improvement at $0.08^{\circ}$ resolution; however, the maximum wind speed still does not match the maximum of $34 \mathrm{~m} \mathrm{~s}^{-1}$ seen in the NOAA data set. The wind speed patterns in the coupled simulations (CPL08) are more intense compared to the atmosphere-only (CCLM08) simulations, and the structures are more delicate. According to Cavicchia and von Storch (2012), the high wind speeds recorded in the NOAA data set may be due to mistral winds, which are not well resolved in simulations.

Most of the medicane features are well resolved at the higher resolution of $0.08^{\circ}$ (Fig. 2). The correct times and locations of simulated medicane formations are not in good agreement with the satellite images and MERRA reanalysis data. This may be due to the small size of medicanes, boundary layer parameterizations, the role of moist microphysics, and deep convection (Tous et al., 2013). Furthermore, the simulations starting 3 weeks before the medicane development and due to no data assimilation procedure, it is thus not possible to follow the real atmospheric conditions, as seen by the medicane tracks in CPL08 and CCLM08, which are significantly different from the MERRA reanalysis data. However, applying spectral nudging to CCLM increases the spatiotemporal characteristic of the medicanes. Thus, the same event is simulated again, this time with the spectral nudging technique applied to CCLM.

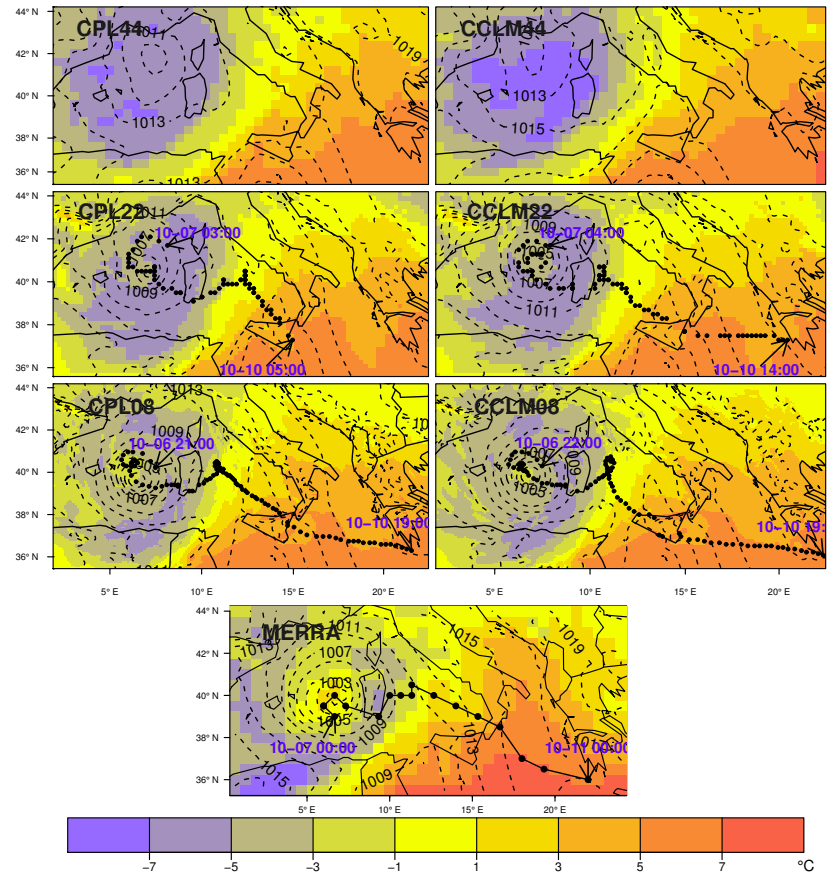

Figure 2. ME08; mean sea level pressure (hPa; dotted contours lines at $2 \mathrm{hPa}$ intervals) and temperature $\left({ }^{\circ} \mathrm{C}\right.$ : colored contours at $2{ }^{\circ} \mathrm{C}$ intervals) at $700 \mathrm{hPa}$ in the coupled and atmosphere-only $(0.44,0.22$, and $0.08^{\circ}$ ) simulations and the MERRA reanalysis data on 7 October 1996 at 18:00 UTC. Black dots represent track of the medicane.

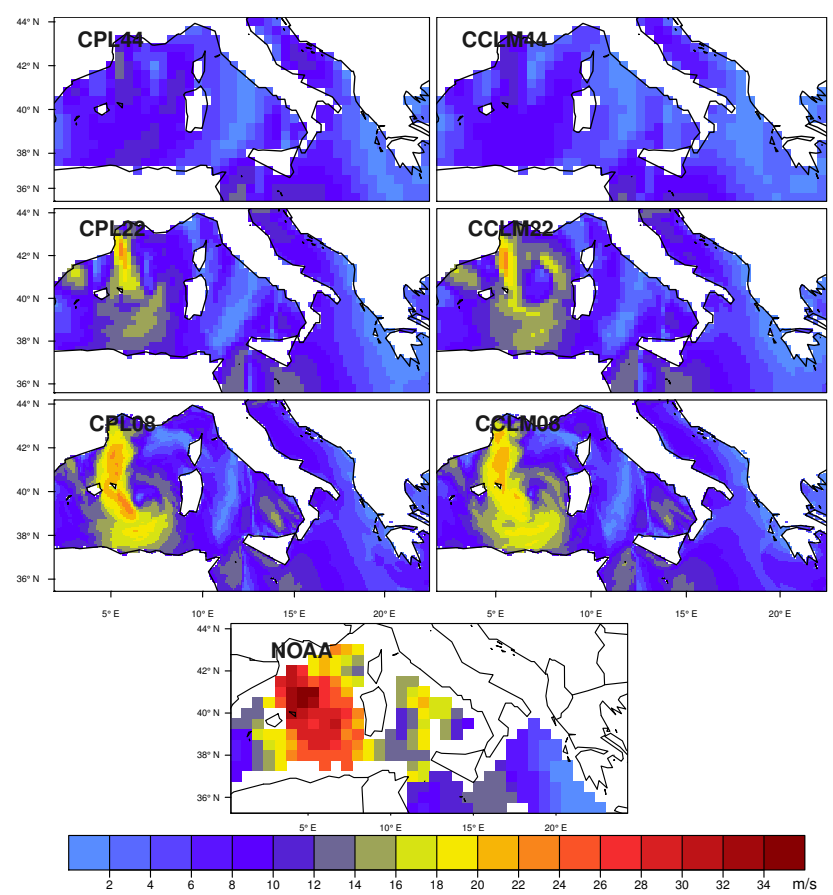

Figure 3. ME08; $10 \mathrm{~m}$ wind speed $\left(\mathrm{m} \mathrm{s}^{-1}\right)$ in the coupled and atmosphere-only $\left(0.44,0.22\right.$, and $\left.0.08^{\circ}\right)$ simulations and the NOAA "Blended Sea Winds" on 7 October 1996 at 18:00 UTC. 


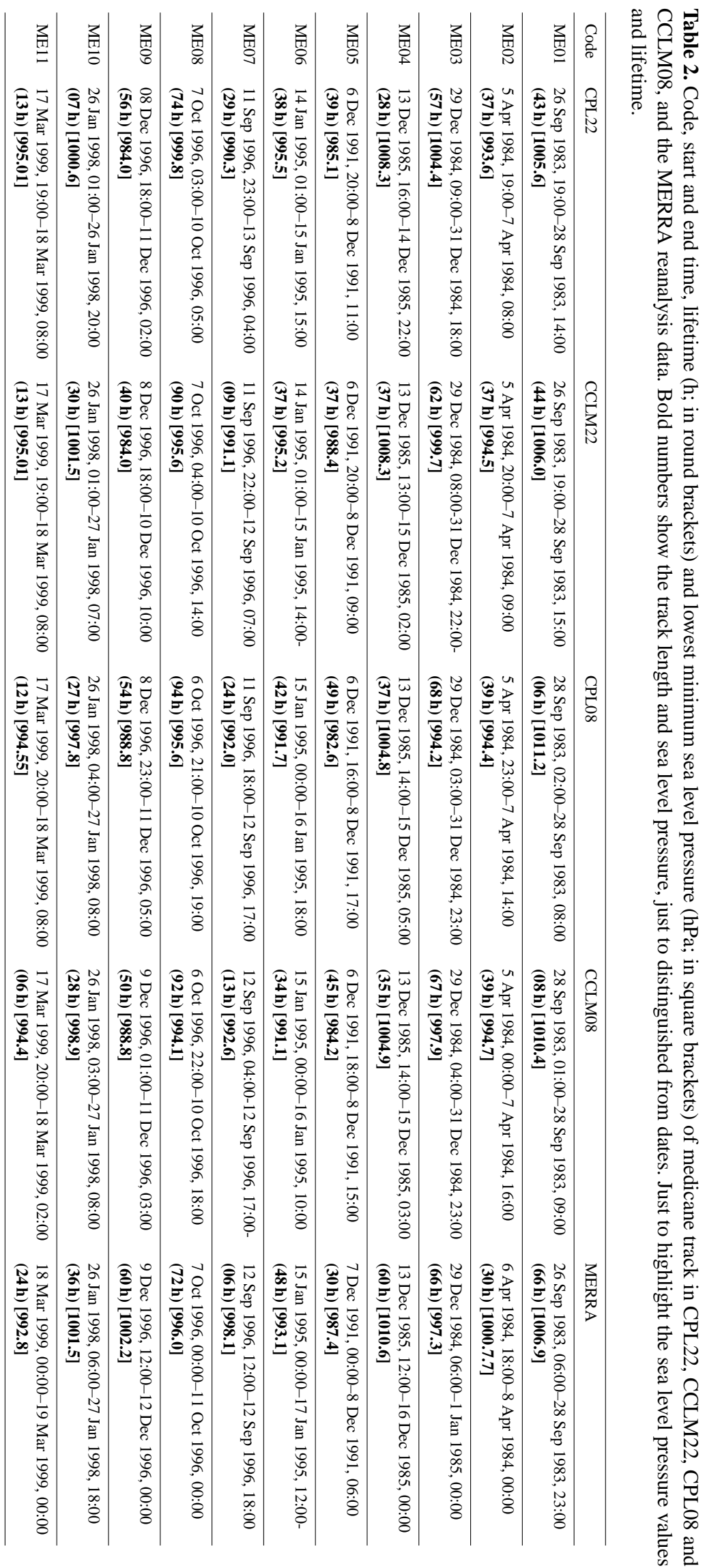




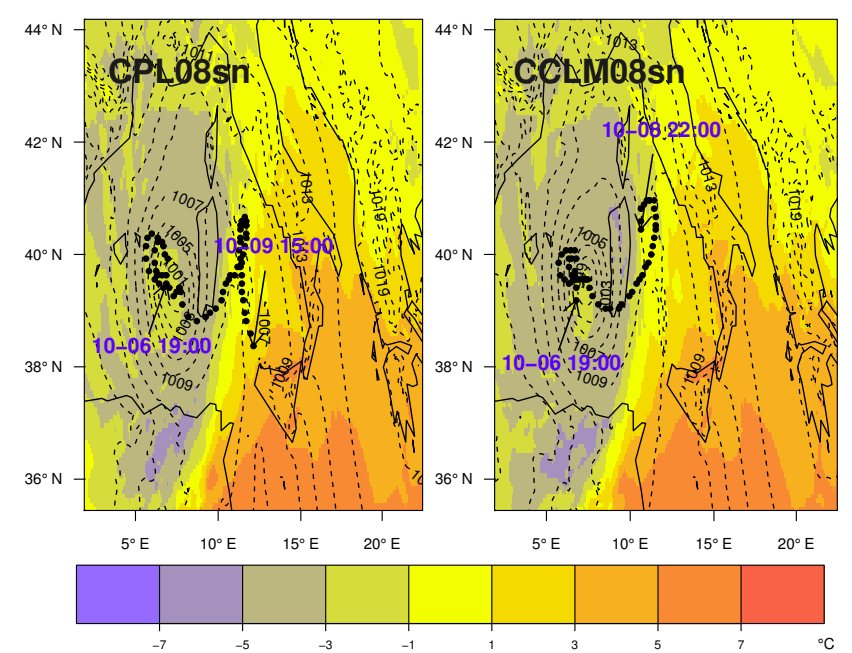

Figure 4. ME08; mean sea level pressure (hPa; dotted contours lines at $2 \mathrm{hPa}$ intervals $)$ and temperature $\left({ }^{\circ} \mathrm{C}\right.$ : colored contours at $2{ }^{\circ} \mathrm{C}$ intervals) at $700 \mathrm{hPa}$ in the coupled and atmosphere-only $\left(0.08^{\circ}\right)$ with spectral nudging simulations, on 7 October 1996 at 18:00 UTC. Black dots represent track of the medicane.

Figure 4 shows the results of the CPL08sn and CCLM08sn simulations on 7 October at 18:00 UTC, along with the medicane track (black dots). The lowest minimum sea level pressure value during a fully developed medicane period is 995.94 hPa in CLP08sn, and $995.34 \mathrm{hPa}$ in CCLM08sn. The lowest sea level pressure values with and without spectral nudging simulations (Table 2) are not very different. The first sea level pressure minimum appeared 3-4 h earlier in simulations with spectral nudging compared to those without. Initially, the location of the medicane in spectral nudging simulations is shifted more to the south, which compares better with the satellite observations and MERRA reanalysis data. Although the timing and location of the medicane is improved by applying spectral nudging as expected (Cavicchia and von Storch, 2012), compared to the satellite observations, the length of the track is reduced in this particular case. The length of the medicane track in CPL08sn $(68 \mathrm{~h})$ is longer than in CCLM08sn (51 h).

In most cases, the length of a medicane's track in spectral nudging simulations is approximately the same as in cases without spectral nudging (Table 2). Figure 5 shows the wind speed patterns in CPL08sn and CCLM08sn simulations on 7 October at 18:00 UTC. The wind speed did not show any improvement in simulations with spectral nudging compared to simulations without spectral nudging (see Fig. 3).

The surface heat fluxes (latent and sensible) play an important role in the formation and evolution of medicanes (Tous et al., 2013). Figure 6 and 7 show the mean sea level pressure, latent and sensible heat fluxes, respectively, on 7 October 1996 at 18:00 UTC along with the medicane track (black dots). The results show that the intensity of the latent and sensible heat fluxes increased with increasing atmospheric

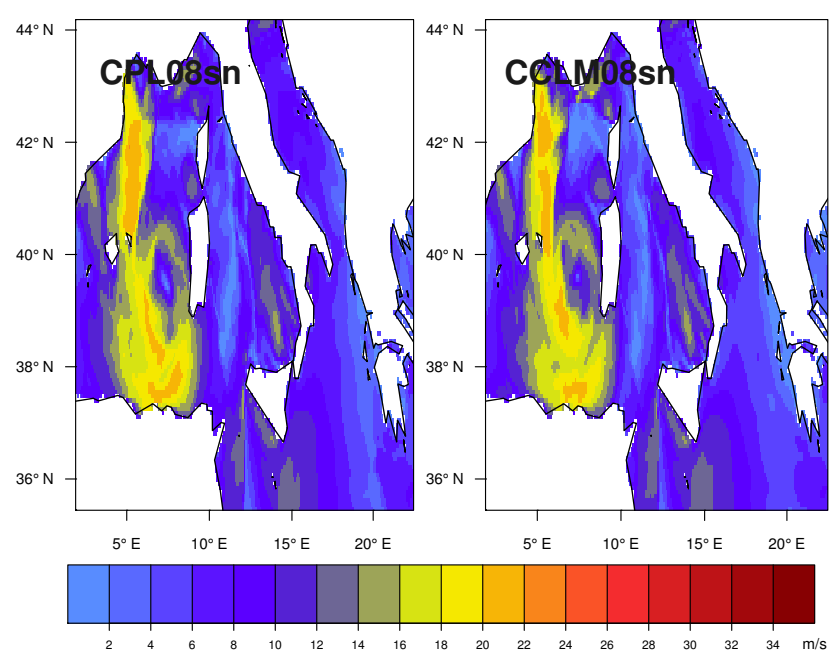

Figure 5. ME08; $10 \mathrm{~m}$ wind speed $\left(\mathrm{m} \mathrm{s}^{-1}\right)$ in the coupled and atmosphere-only $\left(0.08^{\circ}\right)$ with spectral nudging simulations, on 7 October 1996 at 18:00 UTC.

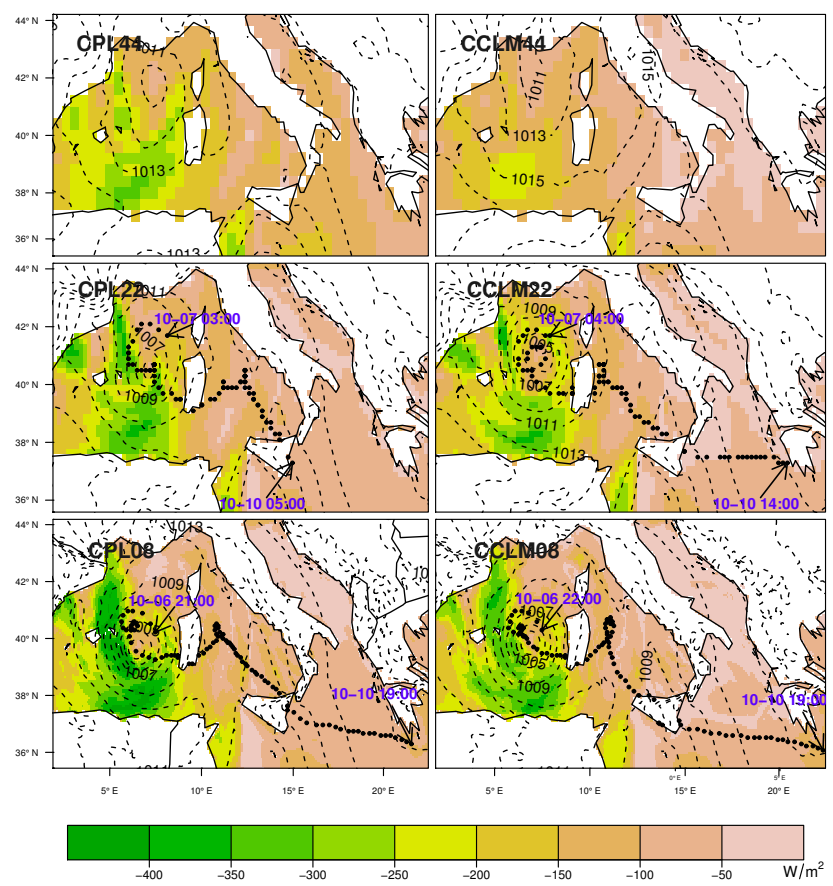

Figure 6. ME08; mean sea level pressure (hPa; dotted contours lines at $2 \mathrm{hPa}$ intervals) and latent heat flux ( $\mathrm{W} \mathrm{m}^{2}$; colored contours at $50 \mathrm{~W} \mathrm{~m}^{2}$ intervals) in the coupled and atmosphere-only $(0.44,0.22$, and $0.08^{\circ}$ ) simulations on 7 October 1996 at 18:00 UTC. Black dots represent track of the medicane. 


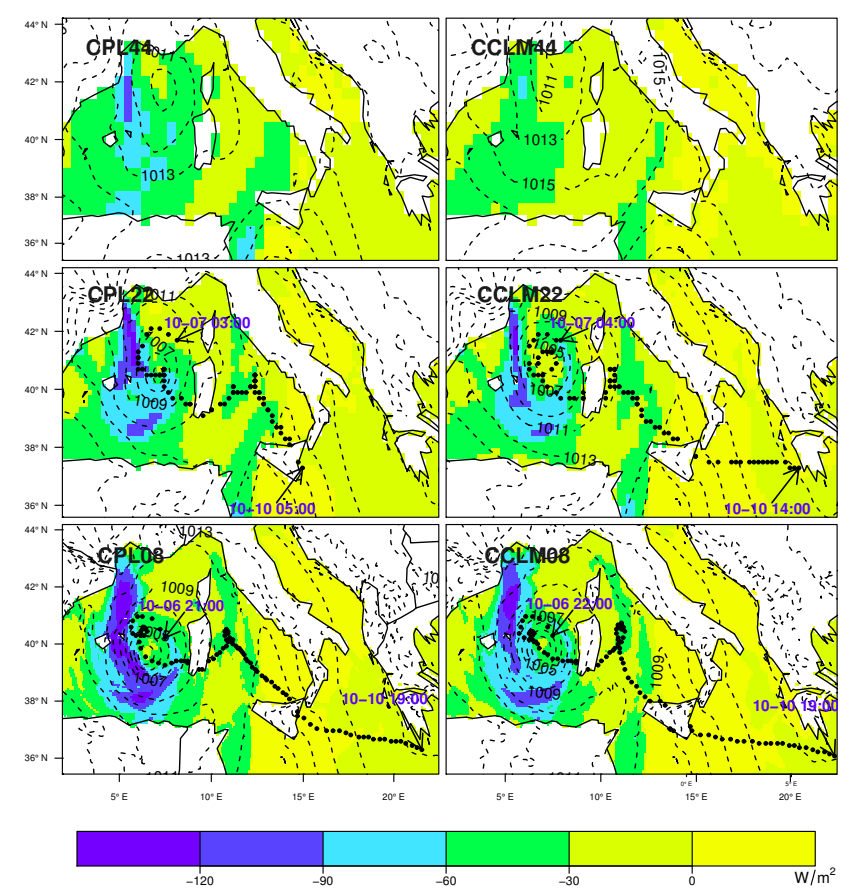

Figure 7. ME08; mean sea level pressure (hPa; dotted contours lines at $2 \mathrm{hPa}$ intervals) and sensible heat flux $\left(\mathrm{W} \mathrm{m}^{-2}\right.$; colored contours at $30 \mathrm{~W} \mathrm{~m}^{-2}$ intervals) in the coupled and atmosphere-only $(0.44$, 0.22 , and $0.08^{\circ}$ ) simulations on 7 October 1996 at 18:00 UTC. Black dots represent track of the medicane.

grid resolution. The CPL08 simulations showed higher absolute values of latent and sensible heat fluxes together with a more intense medicane than the atmosphere-only simulation. Thus, the medicane formation appears directly linked to surface heat fluxes.

Similar to the simulations without spectral nudging, the latent and sensible heat fluxes are higher in the coupled spectral nudging simulations (not shown). The spectral nudging simulations did not show any significant differences in the latent and sensible heat fluxes compared to the simulations without spectral nudging, conforming its low effect.

Higher values of latent and sensible heat fluxes are seen when coupling with the high resolution of the 1-D NEMOMED12 ocean model, as well as the increasing of the atmospheric model resolution. On one hand, the ocean model allows the simulation of ocean meso-scale feature. Stanev et al. (2001) showed that the increasing the ocean model resolution modifies the SST according to the direct simulation of ocean meso-scale activities. In that case, it leads to an increase of $20 \%$ in the ocean heat loss. On the other hand, increasing the atmosphere resolution allows the simulations of new atmospheric fine-scale processes. For example, rain bands over the Gulf of Lions were better simulated at $6.7 \mathrm{~km}$ than at $20 \mathrm{~km}$ in Weather Research and Forecasting (WRF) model (Lebeaupin et al., 2011). Most importantly, wind gusts are better simulated with higher resolution atmospheric mod- els. These changes in the winds can have quantitative effects on the turbulent fluxes (latent and sensible) at the air-sea interface.

The first 11 medicane events listed in Table 1 are also simulated by applying the spectral nudging technique to CCLM in both the coupled and atmosphere-only setups. In most cases, simulations with spectral nudging improved the precision in the time and location of simulated medicanes. A similar conclusion was reached by Cavicchia and von Storch (2012) for atmosphere-only, CCLM simulations. The results show that applying spectral nudging did not significantly improve the wind speed estimates in both the coupled and atmosphere-only simulations. In all spectral nudging simulations, the coupled model performance is improved to the same extent as the atmosphere-only model, showing more intense and finer structure of medicanes in coupled simulations. As mentioned before in this study, our focus is not to address the precision in times and locations of simulated medicanes. We are more interested in examining the ability and added value of the coupled model to simulate medicanes. In subsequent examples, only the results of simulations without spectral nudging are described.

\subsection{Case ME09}

The ME09 case was a medicane event that was observed in the western part of the Mediterranean Sea. According to the satellite observations, the medicane started to develop on 8 December 1996 at 12:00 UTC and lasted for $48 \mathrm{~h}$ (Table 1). The medicane started to develop northwest of Sardinia, and moved towards the Balearic Islands. After reaching the Balearic Islands, it started to move again towards Sardinia and dissipated after crossing it. Figure 8 shows the mean sea level pressure and temperature at $700 \mathrm{hPa}$ in CPL08, CCLM08, and the MERRA reanalysis data on 12 December at 18:00 UTC, along with the medicane track (black dots). The length of the medicane track in CPL08 is $54 \mathrm{~h}, 50 \mathrm{~h}$ in CCLM08, and $60 \mathrm{~h}$ in the MERRA reanalysis data. Although the lowest minimum sea level pressure values are the same in both CCLM08 and CPL08, the length of the medicane track is longer in the latter (Table 2). Figure 9 shows the wind speed patterns in CPL08, CCLM08, and the NOAA data set on 12 December at 18:00 UTC. The wind speed patterns in CPL08 are more intense and in good agreement with the NOAA data set. Compared to the atmosphereonly simulations, the medicane tracks, warm-core structures, and wind speeds are improved in the coupled simulations.

\subsection{Case ME06}

The ME06 event is a well-known medicane that developed in the central Mediterranean Sea with striking similarities to a tropical cyclone. The satellite observations show that the medicane started to develop on 14 January 1995 at 12:00 UTC and ended on 18 January at 20:00 UTC. The eye 


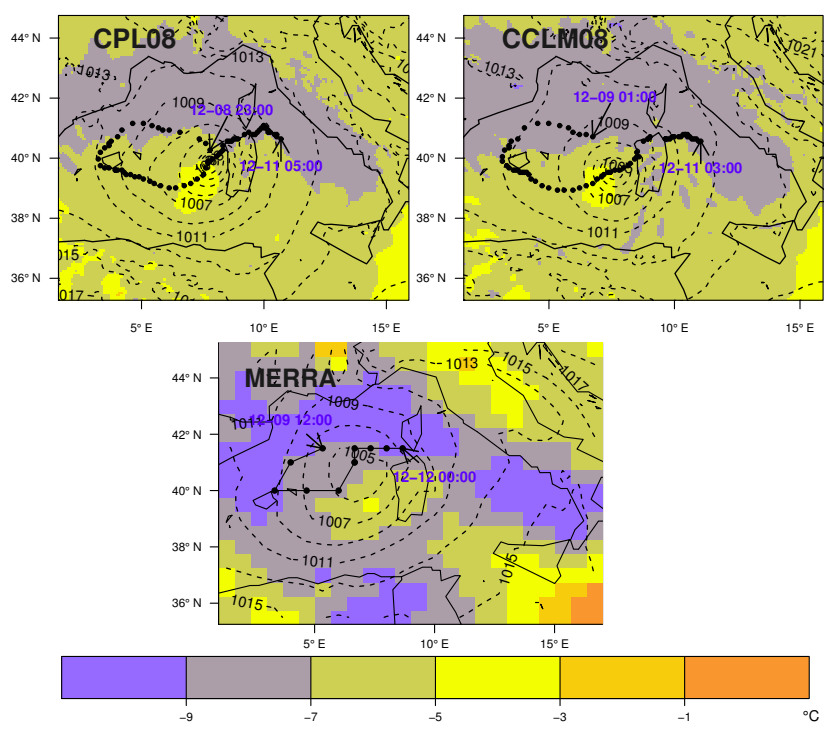

Figure 8. ME09; mean sea level pressure ( $\mathrm{hPa}$; dotted contours lines at $2 \mathrm{hPa}$ intervals) and temperature $\left({ }^{\circ} \mathrm{C}\right.$; colored contours at $2{ }^{\circ} \mathrm{C}$ intervals) at $700 \mathrm{hPa}$ in the coupled and atmosphere-only $\left(0.08^{\circ}\right)$ simulations and the MERRA reanalysis data on 10 December 1996 at 18:00 UTC. Black dots represent track of the medicane.

of the medicane was clearly visible the majority of the time (15 January at 07:00 UTC to 18 January at 06:30 UTC). It was one of the longest medicane events to ever occur in the central Mediterranean Sea (Table 1). According to the satellite observations, a meso-scale low-pressure system moved from the central Mediterranean Sea and reached the coast of Greece in the late night of 14 January. It then started to move towards the coast of Libya. Strong winds, heavy rainfall, and positive temperature anomalies were reported during that time by ships cruising nearby (Cavicchia and von Storch, 2012). The storm dissipated after making landfall in the Gulf of Sirte on 18 January. Figure 10 shows the comparison of mean sea level and temperature at $700 \mathrm{hPa}$ on $16 \mathrm{Jan}$ uary at 12:00 UTC in CPL08, CCLM08, and the MERRA reanalysis data along with the medicane track (black dots). The track does not appear in CPL08, CCLM08, and the MERRA reanalysis data during the first part of the medicane, when it was moving from south to north. This is due to the sea level pressure being less deep and steep in CLP08, CCLM08, and the MERRA reanalysis data. The length of the medicane track in CPL08 is $42 \mathrm{~h}, 34 \mathrm{~h}$ in CCLM08, and $48 \mathrm{~h}$ in the MERRA reanalysis. The lowest minimum sea level pressure values and warm-core structures are similar in both the CPL08 and CCLM08 simulations (Table 2). However, the track length in CPL08 is longer in comparison to the CCLM08 simulations. The medicane tracks in CPL08 and CCLM08 are shifted toward the east compared to the MERRA reanalysis data. Compared to the atmosphere-only simulations, the medicane track and warm-core structure in the coupled simulations (CPL08) are in good agreement with

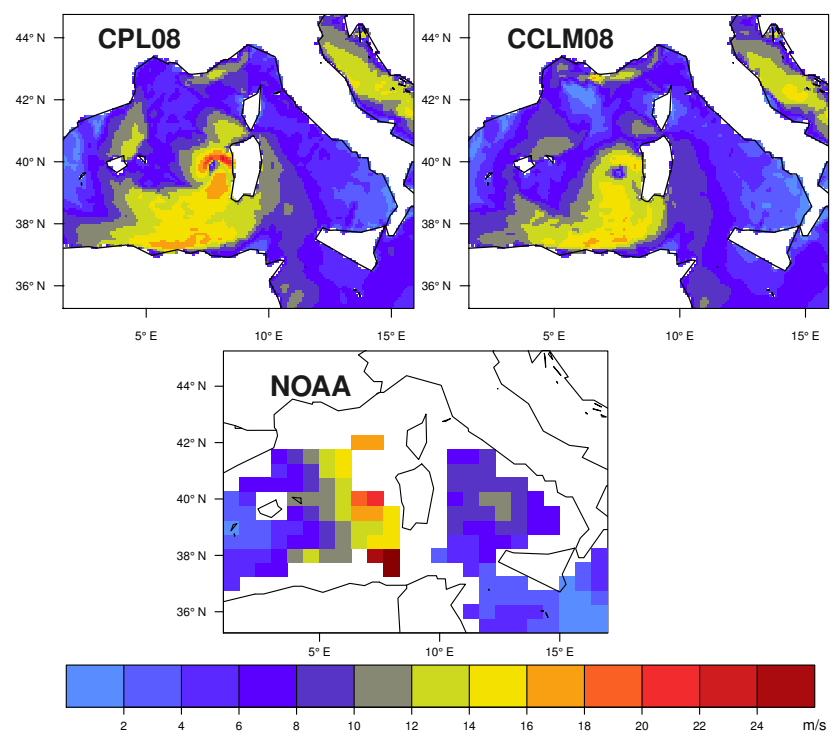

Figure 9. ME09; $10 \mathrm{~m}$ wind speed $\left(\mathrm{m} \mathrm{s}^{-1}\right)$ in the coupled and atmosphere-only $\left(0.08^{\circ}\right)$ simulations and the NOAA "Blended Sea Winds" on 10 December 1996 at 18:00 UTC.

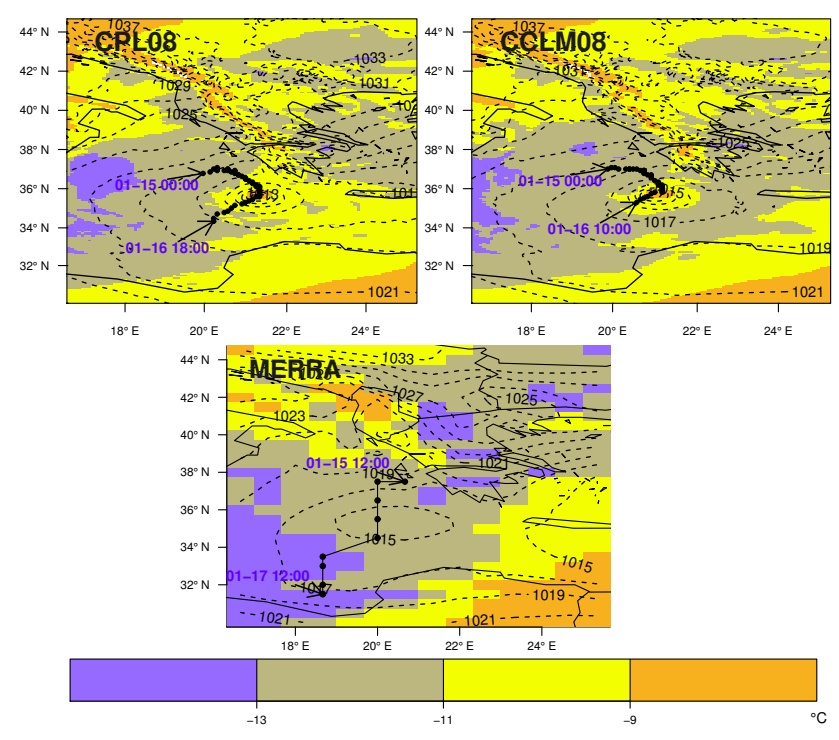

Figure 10. ME06; mean sea level pressure (hPa; dotted contours lines at $2 \mathrm{hPa}$ intervals) and temperature $\left({ }^{\circ} \mathrm{C}\right.$ : colored contours at $2{ }^{\circ} \mathrm{C}$ intervals) at $700 \mathrm{hPa}$ in the coupled and atmosphere-only $\left(0.08^{\circ}\right)$ simulations and the MERRA reanalysis data on 16 January 1995 at 12:00 UTC. Black dots represent track of the medicane.

the MERRA reanalysis data. Figure 11 shows the wind speed comparison in CPL08, CCLM08, and the NOAA data set on 16 January 1995 at 12:00 UTC. The wind speed in CPL08 is more intense and in good agreement with the NOAA data set, but the position of the maximum wind speed is shifted to the east in the simulations. 


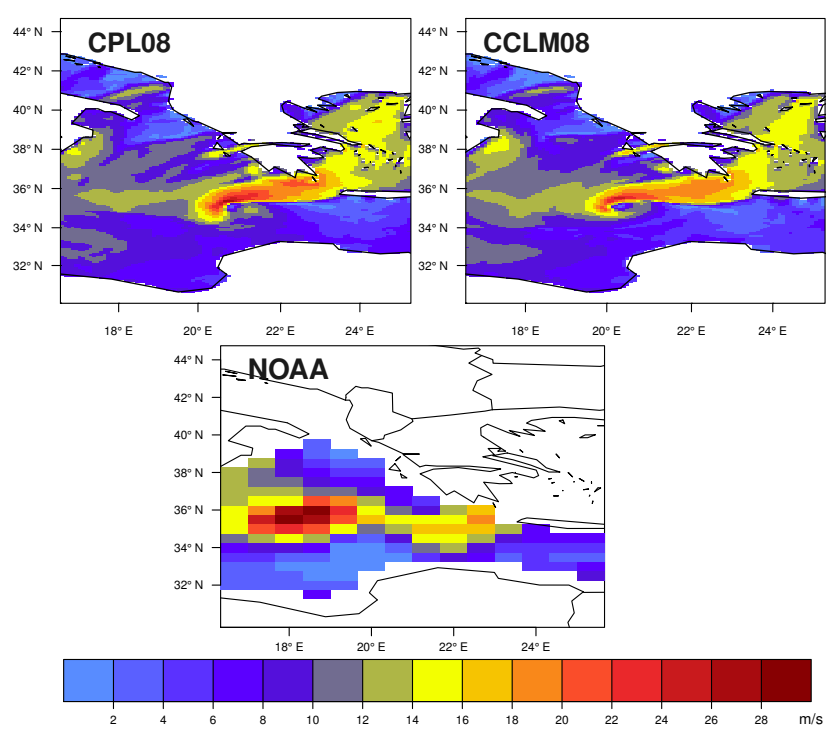

Figure 11. ME06; $10 \mathrm{~m}$ wind speed $\left(\mathrm{m} \mathrm{s}^{-1}\right)$ in the coupled and atmosphere-only $\left(0.08^{\circ}\right)$ simulations and the NOAA "Blended Sea Winds" on 16 January 1995, at 12:00 UTC.

\subsection{Case ME10}

The ME10 medicane event occurred in the central part of the Mediterranean Sea. The satellite observations show a mature phase of the medicane on 26 January 1998 at 12:00 UTC (Table 1). The medicane started to develop in the southeast of the Sicily channel and dissipated after making landfall in the northeastern coast of Libya. The observed lifetime of this medicane was $30 \mathrm{~h}$ (Table 1). Figure 12 shows the comparison of the mean sea level and temperature at $700 \mathrm{hPa}$ on 27 January at 00:00 UTC in CPL08, CCLM08, and the MERRA reanalysis data, along with the medicane track (black dots). The length of the simulated medicane track in CPL08 is $27 \mathrm{~h}, 28 \mathrm{~h}$ in CCLM08, and $36 \mathrm{~h}$ in the MERRA reanalysis data. The first sea level pressure minimum appeared $1 \mathrm{~h}$ earlier in the CCLM08 simulations compared to the CPL08 simulations. The mean sea level pressure is slightly deeper in CPL08 compared to CCLM08 (Table 2), and the warm-core values are approximately the same in both simulations. However, the MERRA reanalysis data show more intense values of mean sea level pressure (Table 2) and warm core. The medicane tracks in CLP08 and CCLM08 are shifted towards the south compared to the MERRA reanalysis data. Figure 13 shows the wind speed comparison of CPL08, CCLM08, and the NOAA data set on 27 January at 00:00 UTC. The wind speed patterns in CPL08 are stronger and finer compared to the CCLM08 simulations, and in good agreement with the NOAA data set.

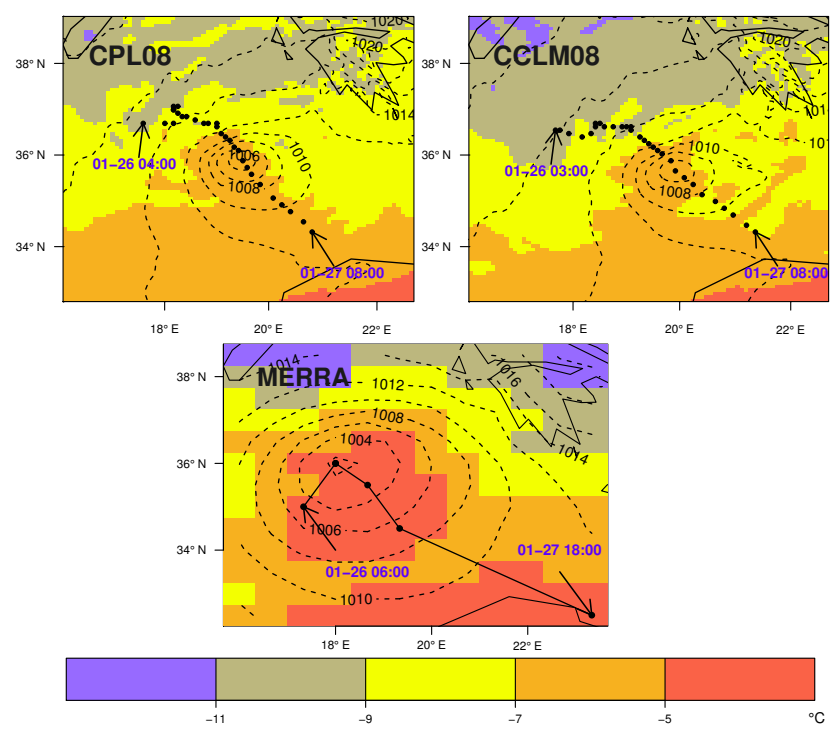

Figure 12. ME10; mean sea level pressure ( $\mathrm{hPa}$; dotted contours lines at $2 \mathrm{hPa}$ intervals) and temperature $\left({ }^{\circ} \mathrm{C}\right.$ : colored contours at $2{ }^{\circ} \mathrm{C}$ intervals) at $700 \mathrm{hPa}$ in the coupled and atmosphere-only $\left(0.08^{\circ}\right)$ simulations and the MERRA reanalysis data on 27 January 1998 at 00:00 UTC. Black dots represent track of the medicane.

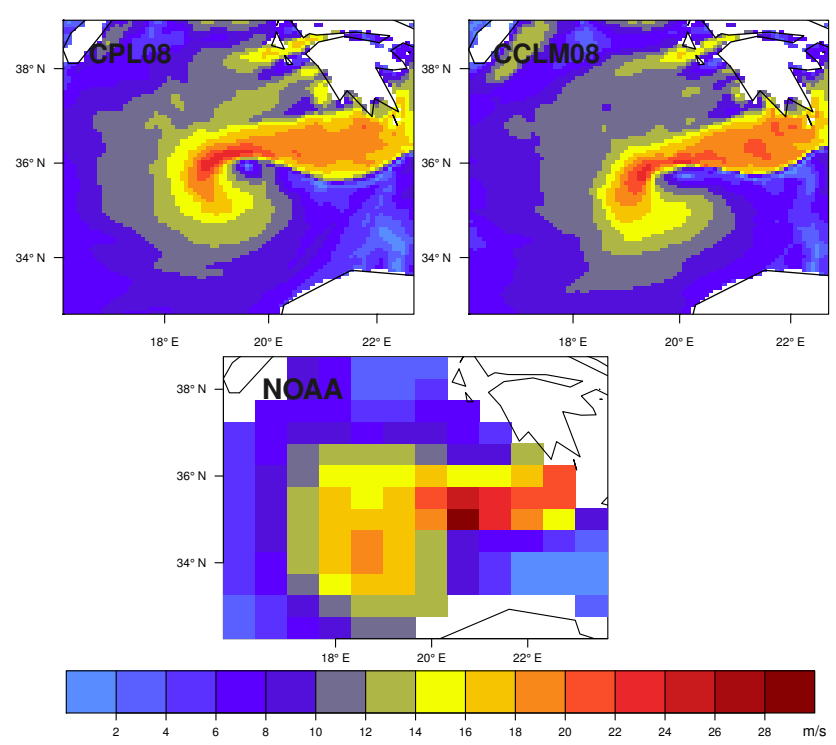

Figure 13. ME10; $10 \mathrm{~m}$ wind speed $\left(\mathrm{m} \mathrm{s}^{-1}\right)$ in the coupled and atmosphere-only $\left(0.08^{\circ}\right)$ simulations and the NOAA "Blended Sea Winds" on 27 January 1998 at 00:00 UTC. 


\subsection{Cases ME01-ME05, ME07, and ME11}

In the remaining ME02-ME05 and ME07 cases, finer structure are only observed in high-resolution $\left(0.08^{\circ}\right)$ simulations. Table 2 shows the lengths of medicane tracks and lowest minimum sea level pressure values of all simulated medicanes. The ME01 case was not well simulated at high resolution $\left(0.08^{\circ}\right)$; the track length is very short in both the CPL08 (6h) and CCLM08 simulations ( $8 \mathrm{~h}$ ) compared to the MERRA reanalysis (66h) data (Table 2). For the ME11 case, the medicane tracks in both the $0.22^{\circ}$ (CPL22; $13 \mathrm{~h}$ and CCLM22; $13 \mathrm{~h}$ ) and $0.08^{\circ}$ (CPL08; $12 \mathrm{~h}$ and CCLM08; 6h) simulations are very short compared to the MERRA reanalysis data (24 h). Tous et al. (2013) investigated the impact of surface heat fluxes on the intensity and trajectories of the 12 medicanes listed in Table 1. They found that surface heat fluxes do not play significant roles in the intensity and trajectories of these two medicanes (ME01 and ME11). This may be the reason that these two medicanes are not well simulated.

Overall results show that there is no significant difference in the lengths of the medicane tracks between the CPL22 and CCLM22 simulations. The mean sea level pressure difference between CPL22 and CCLM22 ranges from 0 to $4.7 \mathrm{hPa}$. However, the lengths of the medicane track in CPL08 are longer than CCLM08, except ME02, where both have the same track length, and ME10 where CPL08 shows a shorter $(1 \mathrm{~h})$ track length compared to CCLM08. The difference between the lowest minimum sea level pressure values in most of the $0.08^{\circ}$ simulations ranges from 0 to $1.6 \mathrm{hPa}$, except ME03, where the difference is slightly higher $(3.7 \mathrm{hPa})$. The results show that warm-core structures are also more intense in the CPL08 simulations compared to CCLM08.

The wind speed is strongly underestimated in all cases of the $0.22^{\circ}$ simulations. However, the wind speed is significantly improved in the $0.08^{\circ}$ simulations. Compared to CCLM08, the wind speed in CPL08 is more intense and in good agreement with the NOAA data set. The results show that $0.08^{\circ}$ is an appropriate atmospheric grid resolution to resolve most of the meso-scale characteristics associated with medicanes in coupled and atmosphere-only simulations. The coupled simulations at $0.08^{\circ}$ also improved the results, particularly the medicane's track lengths, warm-core and wind speed structures compared to atmosphere-only simulations.

\section{Conclusions}

In this study we examined the ability of the coupled atmosphere-ocean model COSMO-CLM/1-D NEMOMED12 with atmospheric grid spacings of $0.44,0.22$, and $0.08^{\circ}$ (about 50, 25, and $9 \mathrm{~km}$, respectively) and an ocean grid spacing of $1 / 12^{\circ}$ to simulate medicanes. The results show that the model's performance depends strongly on the atmospheric grid resolution. The large-scale disturbance is well simulated in all three resolutions. Medicane signals are not observed in the $0.44^{\circ}$ simulations. In the $0.22^{\circ}$ simulations, the mean sea level pressure and warm core are captured, and are more intense and finer in the $0.08^{\circ}$ simulations. The wind speed is strongly underestimated in the $0.22^{\circ}$ simulations compared to the NOAA data set. Most of the medicane features are well resolved at high resolution $\left(0.08^{\circ}\right)$ in both coupled and atmosphere-only simulations.

Compared to the atmosphere-only simulations, the coupled model did not show any significant improvement at 0.44 and $0.22^{\circ}$ resolutions. In the $0.22^{\circ}$ simulations, the coupled and the atmosphere-only simulations did not show any significant difference in the medicane track length. The wind speed and warm-core structures in the $0.22^{\circ}$ (both coupled and atmosphere-only) simulations are not well represented. However, the coupled simulations improved significantly compared to atmosphere-only simulations at higher atmospheric grid resolution $\left(0.08^{\circ}\right)$. The characteristic features of medicanes, such as warm cores and high wind speeds, are more intense in coupled simulations compared to atmosphere-only simulations. In most cases, medicane tracks in the coupled simulations are longer compared to the atmosphere-only simulations, and therefore in good agreement with observations. These results suggest that a $0.08^{\circ}$ grid resolution produces accurate detailed results in medicane simulations, particularly with the coupled model. An atmospheric grid resolution higher than $0.22^{\circ}$ is vital to simulate the medicanes more realistically in both coupled and atmosphere-only models.

The coupled and atmosphere-only simulations with the spectral nudging technique increased the accuracy of times and locations of generated medicanes. However, the simulations with spectral nudging did not result in any significant improvement in the mean sea level pressure and wind speed estimates. In the spectral nudging simulations, the medicane tracks and wind speeds in the coupled simulations are better represented compared to the atmosphere-only simulations, similar to simulations performed without spectral nudging.

The intensity of the latent and sensible heat fluxes increased with increasing atmospheric grid resolution. The absolute values of latent and sensible heat fluxes are higher in the coupled simulations than the atmosphere-only simulations. Thus, the results suggest that intensity of medicanes is strongly linked with surface heat fluxes and fine-scale features at the air-sea interface. The simulations with spectral nudging did not show any significant differences in the latent and sensible heat fluxes compared to the simulations without spectral nudging.

The present study shows that the coupled model is an effective tool for simulating extreme events such as medicanes. The presented coupled model can be a useful tool for studying tropical-like storms, particularly the ocean feedback effects. The impact of coupling on the vertical structures of medicanes and other important parameters such as precipitation and air-sea fluxes should be analyzed in detail. A full three-dimensional ocean model can be used for long-term 
climate simulations and future projections of these extreme events.

Acknowledgements. The authors acknowledge funding from the Hessian Initiative for the Development of Scientific and Economic Excellence (LOEWE) through the Biodiversity and Climate Research Centre (BiK-F), Frankfurt am Main. The authors thank the Center for Scientific Computing (CSC) of the Goethe University Frankfurt am Main for providing computational facilities, especially LOEWE-CSC. We acknowledge Cindy Lebeaupin Brossier, Jonathan Beuvier, Thomas Arzouse, Samuel Somot and Philippe Drobinski for their help for the NEMO-MED12 model and the atmospheric coupling and Eric Maisonnave for his support. We also acknowledge the French GIS and GMMC which have supported the NEMO-MED12 model development. B. Ahrens acknowledges the support from the German Federal Ministry of Education and Research (BMBF) under grant MiKliP: DECREG/01LP1118B. The authors also acknowledge the HyMeX and MED-CORDEX communities.

Edited by: P. Nastos

Reviewed by: two anonymous referees

\section{References}

Akhtar, N.: New approach with a basin-wide single column ocean model set-up to study the Mediterranean Sea dynamics, Master's thesis, Goethe University, Frankfurt am Main, Germany, 2013.

Artale, V., Calmanti, S., Carillo, A., Dell'Aquila, A., Herrmann, M., Pisacane, G., Ruti, Sannino, G., Struglia, M. V., Giorgi, F., Bi, X., Pal, J. S., Rauscher, S., and The PROTHEUS Group: An atmosphere-ocean regional climate model for the Mediterranean area: assessment of a present climate simulation, Clim. Dynam., 35, 721-740, 2010.

Businger, S. and Reed, R.: Cyclogenesis in cold air masses, Weather Forecast., 20, 133-156, 1989.

Cavicchia, L. and von Storch, H.: The simulation of medicanes in a high-resolution regional climate model, Clim. Dynam., 39, 2273-2290, 2012.

Cavicchia, L., von Storch, H. and Gualdi, S.: A long-term climatology of medicanes, Clim. Dynam., doi:10.1007/s00382-0131893-7, online first, 2013.

Conte, D., Miglietta, M. M., and Levizzani, V.: Analysis of instability indices during the development of a Mediterranean tropicallike cyclone using MSG-SEVIRI products and the LAPS model, Atmos Res., 101 264-279, 2011.

Dubois, C., Somot, S., Calmanti, S., Carillo, A., Déqué, M., Dell'Aquila, A., Elizalde, A., Gualdi, S., Jacob, D., L'Hévéder, B., Li, L., Oddo, P., Sannino, G., Scoccimarro, E., and Sevault, F.: Future projections of the surface heat and water budgets of the Mediterranean Sea in an ensemble of coupled atmosphere-ocean regional climate models, Clim. Dynam., 39, 1859-1884, 2012.

Elguindi, N., Somot, S., Déqué, M., and Ludwig, W.: Climate change evolution of the hydrological balance of the Mediterranean, Black and Caspian Seas: impact of climate model resolution, Clim. Dynam., 36, 205-228, 2009.
Emanuel, K.: An air-sea interaction theory for tropical cyclones, Part I: Steady-state maintenance, J. Atmos. Sci., 43, 585-605, 1986.

Emanuel, K.: Genesis and maintenance of "Mediterranean hurricanes", Adv. Geosci., 2, 217-220, doi:10.5194/adgeo-2-2172005, 2005.

Emanuel, K. and Rotunno, R.: An air-sea interaction theory for tropical cyclones, Part II: Evolutionary study using a nonhydrostatic axisymmetric numerical model, J. Atmos. Sci., 44, 542561, 1987.

Ernst, J. A. and Matson, M.: A Mediterranean tropical storm, Weather, 38, 332-337, 1983.

Fita, L., Romero, R., Luque, A., Emanuel, K., and Ramis, C.: Analysis of the environments of seven Mediterranean tropicallike storms using an axisymmetric, nonhydrostatic, cloud resolving model, Nat. Hazards Earth Syst. Sci., 7, 41-56, doi:10.5194/nhess-7-41-2007, 2007.

Gualdi, S., Somot, S., Li, L., Artale, V., Adani, M., Bellucci, A., Braun, A., Calmanti, S., Carillo, A., Dell'Aquila, A., Déqué, M., Dubois, C., Elizalde, A., Harzallah, A., Jacob, D., L'Hévéder, B., May, W., Oddo, P., Ruti, P., Sanna, A., Sannino, G., Scoccimarro, E., Sevault, F., and Navarra, A.: The CIRCE simulations: a new set of regional climate change projections performed with a realistic representation of the Mediterranean Sea, B. Am. Meteorol. Soc., 94, 65-81, 2012.

Homar, V., Romero, R., Stensrud, D., Ramis, C., and Alonso, S.: Numerical diagnosis of a small, quasi-tropical cyclone over the Western Mediterranean: dynamical vs. boundary factors, Q. J. Roy. Meteor. Soc., 129, 1469-1490, 2003.

Hoskins, B. and Hodges, K.: New perspectives on the Northern Hemisphere winter storm tracks, J. Atmos. Sci., 59, 1041-1061, 2002.

Lebeaupin, B. C., Béranger, K., Deltel, C., and Drobinski, P.: The Mediterranean response to different space-time resolution atmospheric forcings using perpetual mode sensitivity simulations, Ocean Model., 36, 1-25, 2011.

Lebeaupin, B. C., Béranger, K., and Drobinski, P.: Ocean response to strong precipitation events in the Gulf of Lions (North-Western Mediterranean Sea): a sensitivity study, Ocean Dynam., 62, 213 226, doi:10.1007/s10236-011-0502-8, 2012.

Luque, A., Fita, L., Romero, R., and Alonso, S.: Tropical-like Mediterranean storms: an analysis from satellite, EUMETSAT 07 proceedings, 2007.

Madec, G.: NEMO ocean engine, Note du Pole de modélisation, Institut Pierre-Simon Laplace (IPSL), France, 27, 1288-1619, 2008.

Miglietta, M. M., Moscatello, A., Conte, D., Mannarini, G., Lacorata, G., and Rotunno, R.: Numerical analysis of a Mediterranean "hurricane" over south-eastern Italy: sensitivity experiments to sea surface temperature, Atmos Res., 101, 412-426, 2011.

Miglietta, M. M., Laviola, S., Malvaldi, A., Conte, D., Levizzani, V., and Price, C.: Analysis of tropical-like cyclones over the Mediterranean Sea through a combined modeling and satellite approach, Geophys. Res. Lett., 40, 2400-2405, doi:10.1002/grl.50432, 2013.

Moscatello, A., Miglietta, M. M., and Rotunno, R.: Observational analysis of a Mediterranean "hurricane" over south-eastern Italy, Mon. Weather Rev., 136, 4373-4397, 2008. 
Niiler, P. P. and Kraus, E. B.: One-dimensional models of the upper ocean, in: Modelling and Prediction of the Upper Layers of the Ocean, edited by: Kraus, E. B., 143-172, Pergamon, Oxford, UK, 1977.

Palmen, E.: On the formation and structure of tropical hurricanes, Geophysica, 3, 26-48, 1948.

Pettersen, S.: Weather Analysis and Forecasting, Mac Graw Hills Book Company, 1956.

Pytharoulis, I., Craig, G., and Ballard, S.: The hurricane-like Mediterranean cyclone of January 1995, Meteorol. Appl., 7, 261-279, 2000.

Rasmussen, E. and Zick, C.: A subsynoptic vortex over the Mediterranean with some resemblance to polar lows, Tellus A, 39, 408425, 1987.

Rienecker, M. M., Suarez, J. M., Gelaro, R., Todling, R., Bacmeister, J., Liu, E., Bosilovich, M. G., Schubert, S. D., Takacs, L., Kim, G. K., Bloom, S., Chen, J., Collins, D., Conaty, A., Silva, A., Gu, W., Joiner, J., Koster, R. D., Lucchesi, R., Molod, A., Owens, T., Pawson, S., Pegion, P., Redder, C. R., Reichle, R., Robertson, F. R., Ruddick, A. G., Sienkiewicz, M., and Woollen, J.: MERRA-NASA's Modern-Era Retrospective Analysis for Research and Applications, J. Climate, 24, 3624-3648, 2011.

Rixen, M.: MEDAR/MEDATLAS-II, GAME/CNRM, doi:10.6096/HyMeX.MEDAR/MEDATLAS-II.20120112, 2012

Rockel, B., Will, A., and Hense, A.: A spectral nudging technique for dynamical down-scaling purposes, The regional climate model COSMO-CLM (CCLM), Meteorol. Z., 17, 347-348, 2008.

Sanna, A., Lionello, P., and Gualdi, S.: Coupled atmosphere ocean climate model simulations in the Mediterranean region: effect of a high-resolution marine model on cyclones and precipitation, Nat. Hazards Earth Syst. Sci., 13, 1567-1577, doi:10.5194/nhess-13-1567-2013, 2013.

Simmons, A., Uppala, S., Dee, D., and Kobayashi, S.: New ECMWF reanalysis products from 1989 onwards, ECMWF Newsletter, 110, 26-35 2006.
Somot, S., Sevault, F., Déqué, M., and Crépon, M.: 21st century climate change scenario for the Mediterranean using a coupled Atmosphere-Ocean Regional Climate Model, Global Planet. Change, 63, 112-126, doi:10.1016/j.gloplacha.2007.10.003, 2008.

Stanev, E. V. and Staneva, J. V.: The sensitivity of the heat exchange at sea surface to meso and sub-basin scale eddies Model study for the Black Sea, Dynam. Atmos. Oceans, 33, 163-189, 2001.

Tous, M. and Romero, R.: Meteorological environments associated with medicane development, Int. J. Climatol., 33, 1-14, 2013.

Tous, M., Romero, R., and Ramis, C.: Surface heat fluxes influence on medicane trajectories and intensification, Atmos Res., 123, 400-411, 2013.

Trenberth, K.: Uncertainty in hurricanes and global warming, Science, 308, 1753-1754, 2005.

Valcke, S.: The OASIS3 coupler: a European climate modelling community software, Geosci. Model Dev., 6, 373-388, doi:10.5194/gmd-6-373-2013, 2013.

Van Pham, T., Brauch, J., Dieterich, C., Frueh, B., and Ahrens, B.: New coupled atmosphere-ocean-ice system COSMOCLM/NEMO: On the air temperature sensitivity on the North and Baltic Seas, Oceanologia, 56, 167-189, doi:10.5697/oc.562.167, 2014.

von Storch, H., Langenberg, H., and Feser, F.: A spectral nudging technique for dynamical down-scaling purposes, Mon. Weather Rev., 128, 3664-3673, 2000.

Wernli, H. and Schwierz, C.: Surface cyclones in the ERA-40 dataset (1958-2001), Part I: Novel identification method and global climatology, J. Atmos. Sci., 2486-2507, 2006.

Zhang, H. M., Bates, J. J., and Reynolds, R. W.: Assessment of composite global sampling: Sea surface wind speed, Geophys. Res. Lett., 33, L17714, doi:10.1029/2006GL027086, 2006. 